\title{
Stable Angina
}

National Cancer Institute

\section{Source}

National Cancer Institute. Stable Angina. NCI Thesaurus. Code C66914.

Angina pectoris which has not recently changed in frequency, duration or intensity. Stable angina pectoris is relieved by rest or administration or oral, sublingual or transdermal antiang inal medications. 